\title{
The Experience Of The Intensive Care Unit In A British Army Field Hospital During The 2003 Gulf Conflict
}

\author{
MJ Roberts, MA Fox, C Hamilton-Davies, S Dowson.
}

\begin{abstract}
Over the last few years the Surgeon General's Department has overseen a major update in equipment scales for medical units in the field; anaesthesia and intensive care. This is to meet the aspiration of the Defence Chiefs, that injured servicemen on active service should receive the same standard of care as available in the United Kingdom.
\end{abstract}

This paper discusses the experiences of the Intensive Care Unit operating within a Field Hospital both during the initial war fighting phase and subsequent peace keeping phase of the 2003 Gulf conflict (OP TELIC). Observations are made on patient activity, treatment strategy, and equipment adequacy.

\section{Introduction}

Since the first GulfWar in 1991 the doctrine of the Army Medical Services (AMS) has adapted to the change from cold war planning, to support for military operations of a more expeditionary nature. The most significant development is the declaration by the defence chiefs that servicemen, ill or injured, should wherever possible, be offered medical care to a standard equal to that which they would receive in the United Kingdom in peacetime (1). To that end, there has been an increased willingness to expend significant resources on the management of the critically ill and injured; casualties who, by necessity, would have previously been treated expectantly on the battlefields of North West Europe. Over the last few years the Surgeon General's Department has overseen a major update in equipment scales for medical units in the field; anaesthesia and intensive care being two areas where there have been the most significant developments. These developments have impacted on recent peace support operations, as in the Balkans, but the 2003 Gulf conflict (Operation TELIC) was the first major operation with the potential for significant numbers of war casualties to test these developments in doctrine and equipment. This paper describes the experience of the intensive care unit of 202 Field Hospital, during the period of conflict, 18 March to 30 April 2003, and outlines the challenges presented when operating in an environmentally and militarily hostile environment.
By way of comparison some data from the immediate post conflict period, 1st May to 20th July 2003, will be presented.

\section{Field Hospital}

202 Field Hospital, a predominantly reservist unit, was mobilized and deployed to the Arabian Gulf in mid March 2003 taking over, on 17th March, a tented field hospital complex 28 miles south of the Iraq-Kuwait border. From the start of hostilities, 202 Field Hospital was the only functioning land based Role 3 facility (providing hospital level care: vida infra) for the initial 9 days of the conflict.

The hospital was a 206 bed complex consisting of an $\mathrm{A} \& \mathrm{E}$ department, operating theatres, intensive care (ICU), X-ray, laboratory, dental, primary care and physiotherapy departments and general medical and surgical wards. As well as general and orthopaedic surgery, the following specialist surgical teams were attached to 202: neurosurgery, maxillofacial surgery, ophthalmology and burns. After the war fighting phase was over, at the beginning of May 2003, 202 Field Hospital moved to Shaibah in southern Iraq and continued to receive casualties until hand over to 33 Field Hospital between 20 and 23 July 2003.

\section{Medical doctrine}

Army medical doctrine envisages a chain of medical care from the point of wounding to definitive medical care in UK. The wounded soldier first receives 'buddy-buddy' aid at the point of wounding and then typically progresses within 1 hour to a Regimental Aid Post (Role 1) for resuscitation. This is the first point at which the casualty is assessed by a doctor and Battlefield Advanced Trauma Life Support (BATLS) protocols are followed. From here he is evacuated to the dressing station of a medical regiment (Role 2) at which a surgical team may perform such surgery (Role $2+$ ) that is absolutely essential to survive further evacuation. From the dressing station the casualty is transferred to the Field Hospital (Role 3) which provides definitive surgical care and is prepared for repatriation to the UK for further surgery, aftercare and rehabilitation (Role 4). The casualty is continually reassessed during this chain of evacuation to ensure that no life threatening injuries are missed and that priority is given to the most serious cases.

North Durham, County Durham. 


\section{The Intensive Care Unit}

The role of the Intensive Care Unit within the field hospital is to provide continued resuscitation and support to allow recovery and discharge to the general wards or sufficient stability to allow safe evacuation to a Role 4 facility. Such repatriation of critically ill patients involves transportation of the casualty over a considerable distance at some considerable risk and is undertaken by the Critical Care Aeromedical Support Team (CCAST) of the Royal Air Force.

The Intensive Care Unit of 202 Field Hospital had eight beds. Of these, four were provided with ventilators at all times and were designated as ICU beds while the remaining four were designated High Dependency Unit (HDU) beds. A further four ventilators and beds could be provided in two Modular Transportable Surgical Facility (MTSF) units. Each MTSF consisted of a theatre unit with one operating table, an ICU with two beds and a support module supplying power, air conditioning, oxygen, water and medical vacuum. This would provide a cleaner and more comfortable working environment, albeit cramped, than the tented unit and was held in reserve for neurosurgical cases.

Patients were monitored using the DatexOhmeda S5 system (Instrumentarium Corp, Helsinki, Finland) and were ventilated when required, with the T Bird VS (Bird Products Corp, Palm Springs Ca). Supplementary oxygen was available from DeVilbiss oxygen concentrators (Sunrise Medical Respiratory Products, Somerset, PA) or cylinders. Syringe drivers were the Braun Perfusor Compact (B.Braun, Melsungen, Germany) and fluid infusions were delivered using iMed Gemini PC-2 infusion controllers (Alaris Medical, Basingstoke, UK). Warming and cooling where necessary was by means of the Bair Hugger (Augustine Medical Inc, Eden Prairie, MN) and Hotline infusion systems (Sims Level 1 Inc, Rockland, MA). A pathology laboratory provided a limited range of biochemical, haematological and microbiological analysis. Bedside testing of blood gases and electrolytes was provided by the i-Stat system (Abbott Laboratories Ltd, Berks, UK).

The unit was staffed by a team of four consultant anaesthetists, all currently active in critical care practice, and 21 nurses-16 of whom had qualifications and at least 2 years experience in critical care.

\section{Admission and Discharge Policies}

It was intended that the unit would provide for intensive care (ICU) patients (two or more organ impairment or advanced respiratory management), and high dependency patients (HDU) (one organ impairment not including advanced respiratory management). The strategy for managing ventilated ICU patients was to either continue resuscitation, in particular correcting hypothermia and hypovolaemia, in order to allow early extubation, or to resuscitate and prepare for early repatriation by the CCAST. Iraqi prisoners of war (EPW) and civilians would be managed entirely within the theatre of operations with a potentially significant effect on length of stay and bed occupancy.

Patients could be admitted to the unit from one of four sources: directly from $A \& E$ for resuscitation prior to surgery, directly from the operating theatres/recovery unit, patients might deteriorate on the wards and need resuscitation or just a higher level of monitoring, or there would be direct transfers of critically ill patients from other medical facilities. The ICU consultants offered an "outreach" policy of attending all major resuscitations in $\mathrm{A} \& \mathrm{E}$ to advise on the requirement for and timing of admission to the unit. Similarly, there would be regular consultation with the anaesthetists in theatre and the recovery staff to ensure that all patients requiring further resuscitation or more extensive monitoring, than was available on the wards, were admitted to the ITU (Table 1). The general wards of a field hospital are only staffed and equipped for basic nursing care and observation. There was no scale for continuous monitoring, or the administration of oxygen so from a cardio-respiratory point of view patients would need to be virtually "street fit" before discharge from the ICU. It was accepted that this would have an impact on length of stay and bed occupancy.

\section{Workload}

During the war fighting phase of Operation TELIC during which 202 Field Hospital was open (17th March - 30th April), 1366 patients were admitted to the hospital and there were 63 admissions to the intensive care unit (Table 2). The majority were male with an average age of 26.8 years. The vast majority were Iraqi, both military and civilian including a significant number were children (Table 3).

Most were admitted from the operating theatres or transferred from other medical units. Few patients were admitted from the general wards (Table 4).

In the absence of complex scoring systems patients were categorised as ICU or HDU patients according to whether they were intubated or not: $44.5 \%$ were intubated at some stage of their stay.

There was a significant difference in the length of stay on the unit between Coalition and Iraqi patients (Table 5): 1.5 v 3.1 days in general and $1 \mathrm{v} 3.5$ amongst burn patients (Table 6).

Figure 1 shows the breakdown of admissions by the specialties involved in their care, several cases involved more than one 
specialty. The majority of admissions involved ballistic trauma; gunshot wounds or shrapnel injuries, with the next most common cause of admission being burns. Sixty two patients with burns were treated by 202 Field Hospital during the conflict, mostly Iraqi and requiring multiple operative interventions (Table 6). Of these $27.4 \%$ required admission to ICU with an average burn of $35.2 \%$ body surface area (Figure 2); these patients constituted a significant workload for the unit. Eleven (64.7\%) were intubated.

After the conflict (1st May - 20th July), the incidence of ballistic/burns trauma reduced to $37 \%$ while the medical admissions including heat injury rose to $47 \%$ and road traffic accidents, resulting in blunt trauma, accounted for $16 \%$ of ICU admissions.

Of the 63 patients admitted during the war fighting phase of the conflict, 45 were discharged to the wards, 17 were evacuated to other medical units either in UK or locally (Table 7). There was one death, a patient who had undergone damage limitation surgery at a forward (Role 2+) facility but who, it was perceived, was not salvageable on admission to 202 Field Hospital. He was admitted to the ICU for a brief period of terminal care.

Table 1. Criteria for admission to ICU.

\begin{tabular}{|l|l|}
\hline A. & Airway at risk \\
\hline B. & $\begin{array}{l}\text { 1. Increased oxygen requirement } \\
\text { 2. Ventilated }\end{array}$ \\
\hline C. & $\begin{array}{l}\text { 1. Hypovolaemic } \\
\text { 2. Acidotic } \\
\text { 3. Bleeding }\end{array}$ \\
\hline D. & Decreased level of consciousness \\
\hline E. & Hypothermic \\
\hline
\end{tabular}

Table 2. 202 Field Hospital Inpatients 17 March - 30 April.

\begin{tabular}{|l|r|}
\hline Total Hospital admissions & 1366 \\
\hline Operating theatre cases & 345 \\
\hline Intensive care admissions & $63(4.6 \%)$ \\
\hline
\end{tabular}

Table 3. ICU Patient Demographics.

\begin{tabular}{|l|l|}
\hline Male/Female & $54 / 9$ \\
\hline Coalition Military & $11(17.5 \%)$ \\
\hline Enemy Prisoners of War & $18(28.5 \%)$ \\
\hline Iraqi Civilian & $33(52.4 \%)$ \\
\hline Non Iraqi Civilian & $1(1.6 \%)$ \\
\hline Age & \\
\hline Mean & 26.8 yrs \\
\hline Range & 6 mnths-67 yrs \\
\hline Number under $\mathbf{1 2}$ yrs & 9 \\
\hline Range & 6 mnths- $11 \mathrm{yrs}(14.3 \%)$ \\
\hline
\end{tabular}

Table 4. Patient location prior to ICU admission.

\begin{tabular}{|l|r|r|}
\hline Operating Theatre & 34 & $(54 \%)$ \\
\hline Forward Medical Units/A+E & 23 & $(36.5 \%)$ \\
\hline Wards & 6 & $(9.5 \%)$ \\
\hline
\end{tabular}

Table 5. Length of stay.

\begin{tabular}{|l|c|c|}
\hline & Coalition & Iraqi \\
\hline Mean length of stay (days) & 1.5 & 3.1 \\
\hline Range & $1-3$ & $1-16$ \\
\hline
\end{tabular}

Table 6. Burns cases 17 March - 30 April.

\begin{tabular}{|l|r|}
\hline Total burns admissions 202 Fd Hosp & 62 \\
\hline Burns admissions ICU & 17 \\
\hline Coalition & 3 \\
\hline Iraqi & 14 \\
\hline Intubated & 11 \\
\hline Mean length of ICU stay (days) & 3.1 \\
\hline Range & $1-8$ \\
\hline LOS Coalition & 1 \\
\hline LOS Iraqi & 3.5 \\
\hline Average \% BSA burn & 35.2 \\
\hline
\end{tabular}

Table 7. Discharge Location.

\begin{tabular}{|l|c|}
\hline Ward & 45 \\
\hline Aeromed UK & 9 \\
\hline Hospital Ships & 5 \\
\hline US Military Hosp & 2 \\
\hline Kuwait Civilian Hosp & 1 \\
\hline Died & 1 \\
\hline Total & $\mathbf{6 3}$ \\
\hline
\end{tabular}

\section{Discussion}

Operation TELIC was the first major conflict in which the Army Medical Services have deployed a significant critical care facility in order to deal with battle casualties. A similar level of sophistication in terms of equipment had been deployed on Operation AGRICOLA 1999 (Kosovo) but on a much smaller scale (2). Experience on that and other peace support operations did not inform as to the scale of ICU utilisation to be expected during a major war fighting operation. The expectation at the outset, that patients would primarily require a high dependency rather than an intensive level of care, was in the event an underestimate of the intensity of the workload; the proportion of intubated and ventilated patients (44.5\%) was significantly higher than expected. In particular it was not appreciated that significant numbers of patients with peripheral ballistic trauma would require a period of post operative ventilation while they underwent further resuscitation.

High dependency patients were still in the majority $(55.5 \%)$. Within a temporary field hospital the general wards are cramped areas 
equipped only to allow simple nursing care and the maintenance of an intravenous infusion. The requirement to maintain the capability of the A\&E department and the onward flow of patients through the operating theatres dictated the role of the HDU. It should act as an area for continued resuscitation and stabilisation, pre and post- operatively, for those patients unfit for admission to the general wards. Unlike peacetime practice, outreach by the intensivists was to encourage admission, as the default, from $\mathrm{A} \& \mathrm{E}$ and theatre recovery; unless the admitting clinicians actively decided the patient was fit for care in a general ward. As a result, free flow of patients

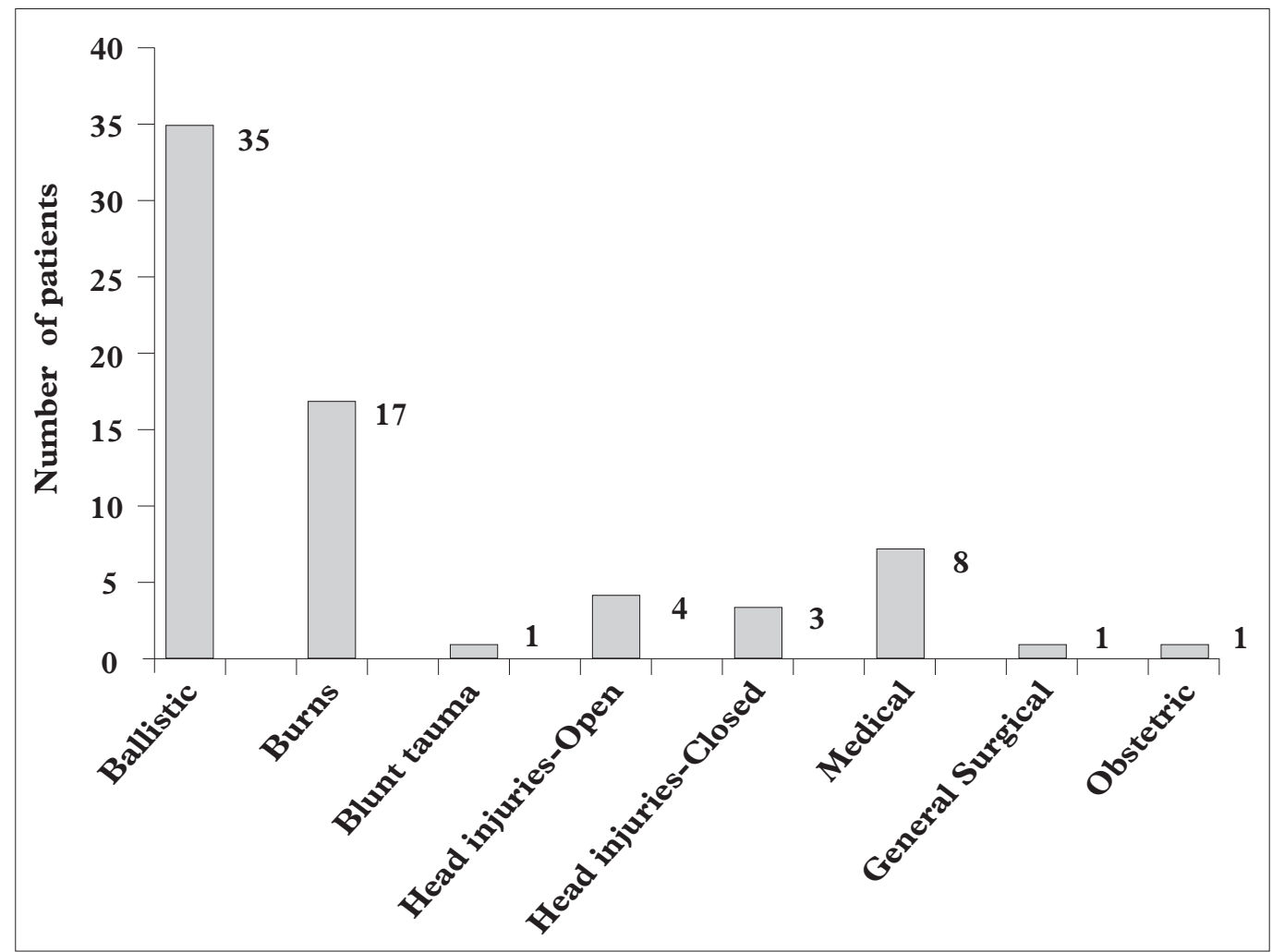

Fig 1. Number of intensive Care Unit admissions analysed by speciality involved in care, during war fighting phase. NB. Some admissions are included in more than one category.

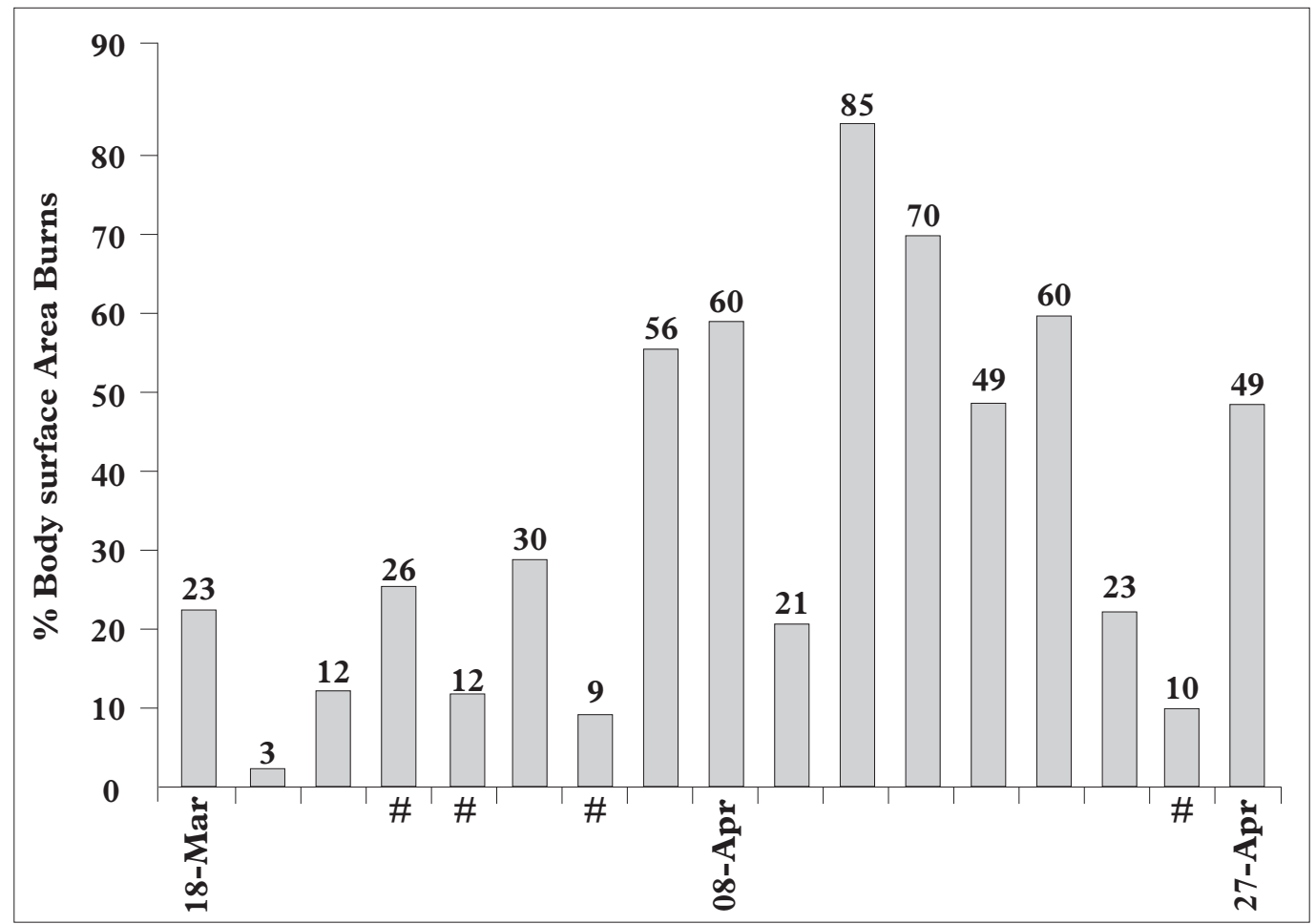

Fig 2. Date of admission to the ICU and \% body surface area of burns of each of the17 burns patients. Patients under 10 years (range 6months-7years)indicated by \# 
through the operating theatres and recovery ward was maintained in contrast to experience on previous operations (cf 32 Field Hospital 1991)(3). This practice also resulted in there being very few subsequent admissions from the general wards (Table 4).

Clearly both the mechanism of injury (Figure 1) and the age of our patients (Table 3) differed markedly from civilian practice. There is a significant difference between the 202 Field Hospital case load and recent military medical practice in other theatres of operation. The proportion of ballistic trauma amongst ICU admissions is in stark contrast to experience on peace support operations in the Balkans where blunt trauma from road traffic accidents, mine injuries and medical admissions predominate. In the later phase of Operation TELIC (15th May - 20th July), the intensive care admissions changed in line with this more familiar pattern.

The majority of the ballistic injuries were to the limbs; this probably reflects the potential lethality of high velocity truncal injuries and the use of body armour by coalition troops. In spite of the peripheral nature of most of these injuries, there was often massive blood loss both prior to and during surgery, not infrequently associated with the triad of hypothermia, acidosis and coagulopathy.

Patients sustaining open head injuries, resulting from ballistic or bayonet wounds, all did well. All patients were conscious on admission, which suggest this group were self-selected for good outcome.

Armoured warfare and fighting in urban areas predisposes to blast injury; perhaps surprisingly therefore, isolated blast injury was not seen? However, several cases of mixed blast/fragment injuries with pneumothoraces, haemothoraces and pulmonary contusions were admitted. Most required surgery for other injuries and all of these required a period of post-operative ventilatory support, but none for longer for longer than 36 hours. Thereafter, adequate gas exchange was achieved with a simple face-mask and inspired oxygen concentrations of up to $60 \%$. There were occasions when patients not requiring intubation, but with significant pulmonary blast injury, would probably have benefited from NonInvasive Positive Pressure Ventilation (NIPPV) or Continuous Positive Airway Pressure (CPAP), however this was not available.

Twenty seven percent of all admissions were patients who had sustained burns, 17 patients with an average of $35.2 \%$ BSA, ranging from $3-85 \%$. The majority were Iraqi civilians who had acquired their injuries in non-battle related incidents. It seems that prior to the outbreak of hostilities there was a policy of not treating major burns, in southern Iraq. Once an alternative to this policy was provided by 202 Field Hospital major burns were attracted from all over the region. These patients presented a very significant workload to the ICU, often presenting several days after their initial injury in a metabolically deranged state. This situation was further exacerbated by the necessary debridement, escharotomy and in some cases amputation. The challenge was to prevent acute renal failure (which we were not equipped to treat) prior to transfer to a definitive burns centre. This was straightforward for coalition troops who were all resuscitated, debrided, dressed, and evacuated to the UK within 36 hours of wounding. However, for the Iraqi casualties this was a major problem in that, as well as their late presentation and poor condition, no effective evacuation plan existed. Each evacuation had to be negotiated on a caseby-case basis either to the UK or within the Middle East.

Typically, Iraqi casualties were not routinely evacuated out of the region. This necessitated longer management on ICU until fit for transfer to the general ward. In contrast, severely injured coalition casualties were repatriated earlier in their illness by the CCAST. This resulted in an ICU length of stay twice as long for the Iraqi patients overall and over three times for Iraqi burns patients. As $80.9 \%$ of all ICU patients were Iraqi this had a significant effect on the bed occupancy.

Children under 12 constituted $14.3 \%$ of the workload on the ICU/HDU (range 3 months - 11 years), all were trauma cases mainly burns and ballistic trauma. It was fortunate that there was significant paediatric experience within 202 Field Hospital, both medical and nursing, although this was unintended at the outset. In contrast, there was no paediatric equipment provided and this proved problematic until suitable items could be obtained from the UK.

Ambient temperature control in a tented, poorly air-conditioned facility was difficult. In particular, the burns patients all exhibited hyperpyrexia, which was exacerbated by the heat of the day. We attempted to minimize this using cooled IV fluids, the ambient setting on Bair Huggers, and tepid sponging in combination with fanned air. Despite airconditioning the midday temperatures within the ITU were often above $33^{\circ} \mathrm{C}$ reaching a maximum of $42^{\circ} \mathrm{C}$ when the air conditioning failed altogether. Several patients with systemic inflammation required increases in their noradrenaline infusion rate during the heat of the afternoon and it became routine practice to increase maintenance fluids as the temperature increased, as otherwise the urine output noticeably decreased. Paradoxically some patients were hypothermic on admission (due either to the very effective air-conditioning in theatre or due to the absence of heating in the theatres, if operating at night).

Even within the ICU the environment was 
extremely dusty, markedly exacerbated during sandstorms. During these storms, ventilator testing was stopped to avoid unnecessary exposure of the ventilators to sand, and a choice would have to be made between the air-conditioning adding to the dust, or the ICU temperature increasing.

Noise was a major problem, from airconditioning and generators, and particularly from the tentage during high winds. In these conditions clinical examination involving auscultation was impossible, leading to a greater reliance on X-ray examination.

It proved impossible to keep flies off the patients, particularly burns and blood stained dressings. In vain attempts to protect exposed burns (e.g. facial), an opened loose gauze swab was applied. Mosquito nets could have been used to advantage, but were not available until later in the operation.

Nuclear, biological and chemical (NBC) alerts were very degrading both for patients and staff. On hearing an alert and in the absence of Collective Protection (COLPRO), the air-conditioning was turned off, staff dressed in full NBC suits and masks (Romeo 4). During one of the early alerts, in the absence of NBC casualty bags, a patient with asthma and pneumonia was draped in his NBC suit and had an oxygen mask applied externally to the inspiratory canister of his gas mask. Although this solution maintained adequate oxygen saturations it was noticeable that anxiety exacerbated the patient's respiratory distress. The ICU is not currently scaled for a NBC proof ventilator (the T Bird does not have a NBC inspiratory filter available). In order to allow ventilation of a patient's lungs in an NBC environment, two ComPAC 200 ventilators (Pneupac, Luton, England) were acquired; these draw in ambient air through an NBC filter and oxygen can be supplemented from a low flow cylinder supply (4). Subsequently it was assessed that the main chemical threat while undercover of tentage was of a vapour agent. In this case the priority is protection of the respiratory tract so the measures described would have been adequate, but only for casualties in possession of their own respirator. There was no immediate solution for the protection of civilians or Iraqi prisoners from vapour, the ideal would have been the provision of chemical casualty bags or the use of collective protection. In the event our defence against these threats was not tested.

Ballistic alerts inevitably interfered with patient care. Clearly protection was not afforded for a direct hit, but even protection from fragmentation injury was not universally available. Whilst the staff had their own helmets and flack jackets, these were not available to the Iraqi casualties or indeed to coalition casualties transferred without their personal kit. This inequality had a disturbing psychological effect on both patients and carers.

Supplementary oxygen is usually supplied in the field hospital by floor standing oxygen concentrators due to the potential difficulty in re-supplying large numbers of oxygen cylinders, a factor influencing the choice of ventilators. The $T$ Bird VS has an internal compressor and is, therefore, not dependant on a high pressure driving gas supply, low flow oxygen is supplemented at a port on the rear of the device. Of note the maximum $\mathrm{FiO}_{2}$ available from these ventilators supplemented by oxygen from concentrators was approximately $55 \%$. If supplemented by cylinder oxygen flowing at $10 \mathrm{l} / \mathrm{min}$ the maximum $\mathrm{FiO}_{2}$ obtainable was greater than $70 \%$, depending on the minute volume.

The only ventilator available capable of pressure controlled ventilation (T Bird AVS) was located in the MTSF but was a gas driven device and very wasteful of available oxygen. Using this device with cylinders would have exhausted the hospital's entire supply of oxygen within 24 hours. In this patient group, even in those with poor lung compliance, the $\mathrm{T}$ Bird VS was perfectly adequate and being unable to use pressure control ventilation was not disadvantageous. Where oxygenation was problematic the strategy was to employ increasing PEEP, reversed inspiratory/expiratory ratio (by decreasing inspiratory flow) and small tidal volumes. As well as lessening the risk of barotraumas, this approach reduces the percentage of oxygen required and therefore the usage of cylinder oxygen supplies.

Drainage of fluid or air from pleural cavities was achieved using the Portex Ambulatory Chest Drainage Kit (SIMS Portex Ltd, Hythe, UK). Whilst effective in the acute phase of resuscitation in the military environment and ideal for transfer, this device could not readily demonstrate the presence of a persisting air leak, nor could it be connected to low-grade suction. A simple underwater seal drain would have been more useful in the Role 3 setting.

There was no effective airway humidification other than intermittent nebulisation, or the use of heat and moisture exchangers (HME). This was a particular problem in the 2 patients who had tracheostomies.

There was no provision for renal replacement therapy on Operation TELIC. Therefore, unit protocol was to ensure adequate fluid replacement even if this may have resulted in fluid overload and transient pulmonary oedema. Although haemofiltration units have been assessed for use in the field, their role if any has not yet been defined. Their use if deployed should be limited to short episodes of filtration prior to evacuation by CCAST to UK in patients unlikely to survive transfer otherwise. As the service offered by the RAF CCAST is on the whole prompt, and most cases of acute 
tubular necrosis develop over days rather than hours, the likely opportunities for appropriate use of filtration would be few. The major limiting factor in whether haemofiltration is deployed in the field will be the uninterrupted availability of experienced nursing staff. The most likely time this treatment mode will be used would be when there is a delay in repatriation, for example when the theatre CCAST is already away or is based in UK. Therefore, any filtration equipment and trained staff should be intrinsic to the field hospital and not the CCAST, as has been considered in the past.

Inotrope and vasopressor usage was minimal. Only severe burns patients exhibiting signs of severe systemic inflammation required infusions of the noradrenaline sufficient to maintain an adequate mean arterial blood pressure and adequate urine output. The unit was not equipped for invasive cardiac output monitoring but, although there is no evidence that this adversely impacted on outcome, such monitoring would have been useful to guide therapy in those vasodilating burns patients. It is possible that a noninvasive system such as the oesophageal doppler might be suitable for field use.

During the initial phase when blood was potentially at a premium and with a predominately young and previously fit population, it was unit policy to accept haemoglobin concentrations in the range 7-8 $\mathrm{g} / \mathrm{dl}$, assuming that haemorrhage had been controlled. However, in those patients requiring aero-med evacuation, higher haemoglobins were sought in view of the potential for unpressurised flight. Initially platelet transfusions were not available. This led to the use of fresh whole blood transfusion in one case to treat profound thrombocytopenia and coagulapathy. Subsequently platelets become available from the host nation. Recombinant Factor VIIa was not available at 202 Field Hospital but was used, apparently to good effect, in other deployed medical units; this is an issue that might be addressed prior to future deployments.

Near patient blood gas and electrolyte monitoring was hampered by the failure of the iStat to function at temperatures in excess of $30^{\circ} \mathrm{C}$. Despite placing the device in the outflow of the air-conditioning system this device would not function during the hottest 4 hours of the day. This variability in availability was an inconvenience rather than a major problem and, considering the proximity of the pathology department, it could be argued that near patient analysis was not really necessary and that these sensitive items should be maintained centrally in the laboratory.

The Datex S5 monitors were impressive in their reliability; despite showing a screen temperature alarm suggesting potential failure when $>33^{\circ} \mathrm{C}$, even at ambient temperatures in excess $42^{\circ} \mathrm{C}$ they continued to function satisfactorily.

Power cuts were relatively infrequent (less than once a day) and most equipment had been selected for the ICU equipment modules in part because they had battery backup; two notable exceptions were the airconditioning and oxygen concentrators. The first was mostly inconvenient, the second required strict attention to cylinder availability.

The MTSFs had not been fully trialed in a desert environment, were extremely unreliable and usually not available for use. When an MTSF was used for neuro-surgical cases it was a very pleasant although cramped environment. However, it was isolated from main ICU and so created an extra drain on manpower. These containerised units were designed to be rapidly deployed and redeployed and probably do not have a role once the main field hospital complex has been erected.

The provision of intensive care and high dependency facilities within the field hospital was highly effective in maintaining the capability of both the resuscitation and operating theatre areas. This was achieved by allowing prompt decanting of seriously ill patients into an area with highly quality equipment and medical personnel skilled in critical care. Whilst Army medical doctrine indicates critically ill patients should be rapidly evacuated, as soon as conditions permit, this is not always possible, particularly for civilians. The equipment scales should be revised to acknowledge that the facilities for rapid evacuation may not always be in place and that the later complications of severe injury may need to be managed in theatre. Dealing with any civilian population, paediatric casualties are inevitable and the ICU must be adequately equipped to treat such patients. Notwithstanding these observations the ICU/HDU was highly effective, and in combination with excellent support from the CCAST evacuation team, prevented any unavoidable mortality.

\section{References:}

1. Hawley A. Trauma Management on the Battlefield: A Modern Approach. I $R$ Army Med Corps. 1996;142:120-125.

2. Roberts MJ, Salmon JB, Sadler PJ. The provision of Intensive Care and High dependency in the Field. F R Army Med Corps.2000;146:99-103.

3. Adley R, Evans DH, Mahoney PF, et al. The Gulf war: anaesthetic experience at 32 Field Hospital Department of Anaesthesia and Resuscitation. Anaesthesia. 1992;47:996-9.

4. Roberts MJ, Bell GT, Wong LS. The CompPAC and PortaPAC portable ventilators bench tests and field experience. $f R$ Army Med Corps. 1999;145:73-7. 